\title{
MANUEL BANDEIRA, TRADUCTOR E INTÉRPRETE DE SOR JUANA INÉS DE LA CRUZ
}

No afirmamos nada nuevo al decir que las relaciones entre las dos literaturas más importantes de la Península Ibérica, la española y la portuguesa, nunca fueron, a través del tiempo, ni numerosas ni mucho menos sistennáticas, a excepción de ciertos momentos particulares, consecuencia de determinadas circunstancias historicas, que influyeron también en la cultura, como sucedió en los sesenta años de la dominación española en Portugal. Nadla nuevo tampoco, si se afirma que los estudios de tales relaciones no fueron, por consiguiente, más que catsuales y episcidicos; por regla general, el interés de tno de los dos paises por el otro no lat ido más alla del simple interés de determinarlos escritures o, en cualcquier caso, de personalidades aisladas del mundo de la cultura o del pensamiento. Piénsese, por ejemplo, en el interés por Lispaña por parte de los mayores representantes de apuel excepcional moriniento de ideas y artístico que fue el realismo portugués en los últimos decenios del siglo xix, desde Antero de Quental a Oliveira Martins, como asimismo en la atención despertada por Portugal en los hombres de la generación española del Noventa y ocho, con Unamuno a la cabeza. Súlo en años más recientes la crítica ha comenzado a preucuparse de echar las bases necesarias para un examen detenido de tales relaciones y su consiguiente valoración, aunque sólo sea en los límites de un estudio sobre nomentos específicos o incluso de determinadas personalidades ${ }^{1}$.

1 Queremos citar concretanchte algumos de los trabajos en este campo, apareciclos estos viltimos años: Josti $\lambda$ Rus $\lambda$ InNTrs, (jingora y la poesia porluguesa

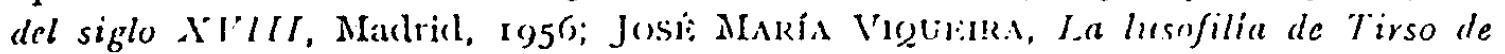

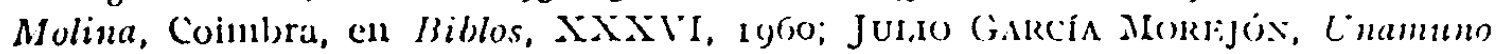
y l'orlugal. Madrid, $19 G_{4}$; Luis Kosales, La poesia corlesana, en el volumen $E l$ sentimiento del desengaño cn la poesia barroca, Malrid, Igor, (clel mismo año es el múmero 3 de la revista lis:boeta Espiral, dedicado en gran parte al mismo tema). Contribuyeron también a estimular el estudio de tales relaciones entre ambas literaturas las obras de algunos estudiosos extranjeros, resile los listudios hispano-

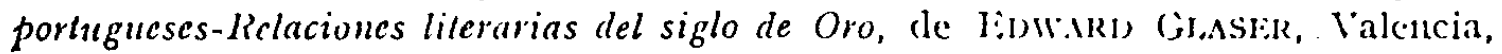
I957, a los listudios sobre las letras en el siglo XVIII (Temas españoles. Temas hispano-poringucses. Temas hispano-italianos,) del autor del presente trabajo. 
Al europeo que considere semejante situación se le ocurrirá preguntarse, espontáneamente, si el estado de las relaciones entre las literaturas en lengua española y portuguesa de América será sustancialmente análogo al presentado por el de las dos literaturas en Europa. Lis una pregunta fue de europeo ligicanente puede plantearse, an cuando no se encuentre en situación de dar por si mismo una respuesta; pero servirá para tratar de buscar una orientación o para detenerse en determinados casos, que podrán muy bien representar capítulos concretos del libro ideal que ciertamente debiern escribirse sobre tales relaciones y que esperamos que algún día se escriba.

Con ese espíritu hemos fijado nuestra atención sobre un episodio en torno a las relaciones entre los mundos culturales representados por ambas lenguas en el siglo xvi, y, más en concreto, sobre las repercusiones de tal episudio en nuestros días. Se trata, en relación al siglo xvir, de la correcta polémica que mantuvieron el portugués P. António Vieira y la mejicana Sor Juana Inés de la Cruz ${ }^{1}$; y, en nuestros días, del in-

1 lil argumento hit sido tratado recientemente. Jil publicista mejicano $\Lambda r_{-}-$ lionso) Junco hat escrito solse el mismo (Antonio Vicira en Mexico. La Carla Allonagúrica de Sor Juana Inis de la Cruz) en el Arquivo Hislórico de Porlugal. I,ishoa, vol. I (1932-3.1), pl). 2\$8-302, clanclo cn síntesis la historia de la controversia. l'ero se ha ocupado mís en particular el ilustre estuclioso francés ROBlikr RiCARD cu su articulo Antunio l'ieira et Sor Juana Inés de la Critz (Bulletin des IEtude's Portugaises at de l' Institut Français au Portugal. Coimbra, Nouvelle Série, II, 1 !) $\$$, 1p). I-34), redactanlo con la finalidad cle poner al corriente al público francés solbre la conocila contienda literaria. Ricard recuerda que Sor Juana escribió la famosa Carta después de muchas vacilaciones - todas ellas sugericlas por el respeto que sentía hacia el P. Ticira, hacia la Orden de los Jesuitas y hacia Portugal-, Y sólo ante la presión de poner por escrito cuantas consideraciones habia hecho en forma privala en torno al sermón del P. Vieira. A juicio de'Ricard, la Carla -licnagórica es un udocument plus curieux qu'adurirable», y alextravagance de Vicira était telle que la réfutation devenait facile” (ob. cit., p. I I). Recuerda Ricard la difusión de la obra del P. Vieira en Méjico, gracias tambićn al prestigio de gue gozaba en el pais la ()rien de los Jesuitas (para lacer el elogio del l'. Aven(laño se le definió nel Vieira mejicanon). Subraya además que en Portugal - donde se llegó a cscribir una Apologia a favor do R. P. Antonio Vieyra (I,isboa, 1727) jor parte de una religiosa agıstina, Sor Margarida Ignácia- no se guardaba rencor algumo laicia Sor Juinil, cuỵas objeciones al P. Vieira son sólo de carácter dialectico (el estilo, lo acepta, pues ambos escritores pertenecen a la kagudeza barroca), y que el l'. Vicira cncontró defensores, si bien en forma mesurada, frente a Sor Juana, inchuso cu Iispaña, comenzando por el P. Isla y leijoo. I,o que interesa tambien, en las piiginas de Ricarcl, es la constatación de que la historia de la controversia "P. Vicira-Sor Juana" poclria recibir nueva luz de un registro y un examen mís escrupulosos de las bibliotecas de Jispaña, l'ortugal y Méjico. Iin ryo7 ha apareciclo en Italia ma breve monografia sobre Sor Juana Inés de la Cruz, de DARIO PUCCINI. 
terés hacia tal escritora y poetisa por parte del ilustre poeta (modernista") brasileño Manuel Bandeira, fallecido hace poco tiempo (r855I968). Liss conocidísimo el comentario crítico hecho por Sor Juana Inés de la Cruz al Sermino do Mandalo pronunciado por el P'. António Vieira

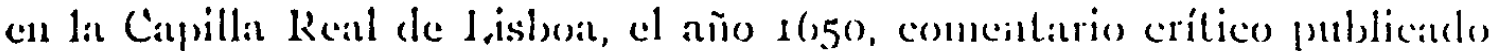

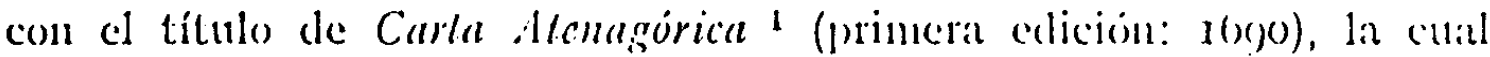
dio ocasión a una segunda corla, ésta de Sor lijlotea de la C'ru\% (sendirnimo de D. Manuel lienánde\% de Santa Cruz, obispo de I'uebla), la que, a su vez, inspiró a Sor Juana la no menos famosa Respuesla a Sor Filotea de la Cruz. Objeto de la fraterna controversia entre las tres grandes personalidades religiosas, dos de ellas, al menos, famosas figuras literarias, el P. António Vieira y Sor Juana Inés de la Cruz, fue en aquellos escritos, como es notorio, el nuevo mandamiento daclo por Cristo a los hombres: "Mandatum novum do vobis, ut diligatis invicem", y "Sicut dilexi vos, ut vos diligatis invicem») (Juan, XIII, 3.t), al cual cl P. Vicira anadc, conno aclaración contral a las veinte piginats densats, a imprenta, cu las fue se conticne su famoso sermón, la precision signiente: "ג novidarle do mandamento e do amor não está con os homens se amarem mos ans outros: está em que o amor com que se amatrem scja paga de amor com que Cristo os amou. Os homens amam a fim de gue os amem; Cristo amou-nos a fim de que nós nos amemos". Y crin la finura inagotable y capilar de la lógica y del silogismo que distingue, dentro del clima barroco, al barroquismo del P. Antúnio Vieira, se divierte éste en poner de mayor relieve la fina delicadeza de los tres hechos en los que San Agustin, Santo Tomás y San Juan Crisóstomo hacen consistir el amor de Cristo hacia los hombres: a su muerte por los hombres que, seguin San Agustin, es la major muestra de delicadeza por parte de Jesús, opone el P. Vicira el hecho de ausentarse de los hombres (pues Jesús amaba más a los hombres que a la propia vida); al quedarse Cristo en la Iiucaristía, la prueba de mayor fineza por parte de Jesús, según Santo 'Iomás, contrapone el P. Vicira el haberse privardo de los sentidos en la Eucaristía, es decir, el hecho de no rer a los hombres aun estando presente; y a la acción humilde de lavar los pies a los Aprostoles, que representa a los ojos de San Juan Crisústomo la delicadeza más fina de Cristo, el P. Vieira opone el hecho de lavárselos no sólo a los once Apóstoles fieles (que sería una correspondencia de amor por amor), sino al propio Judas (acto de amor como pago al odio).

1 Iis sabido que el adjetion le fue dacho a la Carla, en la princra edicion, por el obispo de l'uebla, de quich hablaremos mis aclelante, y que significa: aligna de la sabiclutia de Minervan, como explica D. lizi:qunitr. A. Ciliviz en su Ensajo de psicología, 1) 300. 
A todo esto responde por su parte Sor Juana Inés de la Cruz. Sutil y hábil, como es, en el silogismo, tanto cuanto pueda serlo el P. Vieira, procede en su critica al jesuita portugués con una serie sugestiva de silogismos, en los que la agudeza de su razonamiento va de la mano con la habilidad de su exposición, prefiriendo la opinión de San Agustín a la del jesuita portugués y atribuyendo a este último falta de rigor en su argumentación, por lo que se refiere a los otros dos: en relación con Santo Tomás (que, a propósito de la Eucaristía y de los sentidos, ha hablado "en general»), el P. Vieira es acusado de argumentar "en forma específicay, y en relación con San Juan Crisóstomo (que ha hablado de "causa"), el P. Vieira responde refiriéndose a "efectos". $Y$ con férrea lógica... barroca llega por su propia cuenta a la conclusión de que cuesta más a Dios el no hacer beneficios a los hombres (cuando no los hace es porque los hombres los convertirian en su propio daño) que el hacerlos, siendo por consiguiente la mayor fineza por parte de Dios el suspender sus beneficios más que el concederlos. Y dice también: "Ein Dios mayor beneficio es no dar, siendo su condición natural, porque no nos conviene, que dar siendo tan liberal y poderoso. $\mathrm{Y}$ asf juzgo ser ésta la mayor fineza que Dios hace por los hombres" ${ }^{1}$.

Iis asimismo conocido que la Carla Alenagórica causó una gran impresión en el mundo iberoamericano, donde el P. António Vieira era muy estimado, con notable admiración, al mismo tiempo, por parte de los jesuitas de que una pobre religiosa se atreviese a alzar su voz, desde la absoluta soledad de un desconocido convento de Méjico, con indudable luminildad pero con clara conciencia a la vez de cuanto estaba haciendo ( $\mathrm{y}$ evidentemente lo sentía como un auténtico deber), contra un predicador de la fama del P. Vieira. Y las críticas, dudas y murmuraciones fueron muchas; sin embargo, ninguna de ellas osó atacarla o denunciarla desde el punto de vista de la ortodoxia religiosa, apareciendo todos como impresionados por la seguridad con la que, bajo una actitud humilde (humildad sincera, pero sin renuncias psicológicas), intentaba ella, una pobre religiosa, esclarecer, o por mejor decir, defender indirectamente, su propia intervención y sus propias opiniones.

Y tanto es verdad, que el escrito que responde en forma directa a la Carta Atenagórica de la religiosa fue la así llamada Carta de Sor Filotea de la Cruz, con la cual el ya citado obispo de Puebla trataba de alentar a Sor Juana, en la manera más delicada posible, a trasladar su propia actividad literaria del campo de la prosa al de la poesfa, a ejemplo de Santa

1 P. 439 del tomo IV de las Obras completas de la escritora (edición de la -Biblioteca Americanan del Fondo de Cultura Económica de México-Buenos Aires, 1957, bajo la dirección de Alberto G. SALCEDA). 
Teresa y otros autores, con el fin de utilizar mejor todavía sus admirables dotes, tan puestas de manifiesto ya en la prosa, como demuestra la Carta A tcnagórica por ejemplo... Y es bien sabido que de aquella fraterial y respetuosa sugerencia nació la admirable Respuesta a Sor Filotea considerada descle cntonces como "uno de los más admirables cnsayos autobiográficos en lengua españolan, a juicio de li. $\Lambda$ nderson Imbert ${ }^{1}$, difícilmente superable en cuanto a la forma, y sugestivamente seductora en cuanto a sus ideas ${ }^{2}$. Y tal Respuesla presenta claranente dos aspectos a cual nuás interesante: el de una hábil aceptación, por parte de Sor Juana, del delicado consejo del obispo de Puebla de que hace bien dedicándose a la literatura ${ }^{3}$, y el de reanudar el discurso, por lo que se refiere al P. Vieira, que en un cierto sentido tal vez le interesa más, aunque sepa disinularlo con gran habilidad; aspecto éste en el que aparece claramente la libertad de pensamiento de Sor Juana. Se trata de una libertad a todas luces excepcional, si se tienen en cuenta dos factores bien precisos, de los cuales 110 sería fácil decir cuál es más comprometido: su condición de religiosa, y esta misma condición en su propia época y circunstancias; la libertad de una persona que, en nombre de la verdad y por anor a la verdad, no se preocupa lo más mímimo del peligro de ser incluida en la lista de las personas sospechosas de matices o detalles racionalistas, en el clima del siglo xvir (piénsese en la influencia del Discurso del método de Descartes); una libertad que acepta siempre abiertamente las leyes de la buena educación y del buen gusto, pero que, al mismo tiempo, defiende en modo tan absoluto como categórico

1 P. 65 de su Historia de la Literatura Hispanoamericana, México-Buenos Aires, I'ondo de Cultura Liconómica, 1954.

2 Véase a este propósito la presentación del arriba citado ANDERSON IMBERT, en su obra mencionada, pp. 64-7o, que reconstruye con amplias y oportunas citas la atmósfera espiritual y artística de la religiosa.

- Expresa todo esto en un discurso habilisimo, en una exposición discursiva propia de un gran ensayista, que lace dificil una selección de citas, por lo que nos limitaremos a una solamente: "Desde que ne rayó la primera luz de la razón, fue tan vehemente y poderosa la inclinación a las letras, que ni ajenas reprensiones - que he tenidlo muchas-, ni propias reflejas - que he hecho no pocas-. han bastado a que deje de seguir este natural impulso que Dios puso en mi" (ob. cit., p. 444) (pero que acompañaremos de una reflexión suya que pone en evidencia la sabiduria alcanzada por la religiosa en torno a la melancolía de las cosas humanas: "Pues por la -en mil dos veces infeliz - habilidad de hacer versos, aunque fuesen sagrados, ¿qué pesadumbres no me han dado o cuáles no me han dejado de dar? Cierto, señora mia, que algunas veces me pongo a considerar que el que señala —o le señala Dios, que es quien sólo lo puede hacer- es recibido como enemigo común, porque parece a algunos que usurpa los aplausos que ellos merecen o que hace estanque de las admiraciones a que aspiraban, y asi le persiguenin, ob. cit., pp. 452-453). 
la propia dignidad y la propia independencia de juicio; la libertad, en fin, que una tal persona, por respetarla en las demás, exige para sí misma. Interviniendo, por ejemplo, en las muclias y contrastantes interpretaciones dadias a las palabras de San Pablo "mutieres in Jicclesiis taceant" (I Cor. XIV, 34), se pregunta clla si la Carta Alenagórica fue, por ello, tu1 "crinen" (en el sentido de que "ni en secreto se permita escribir ni estudiar a las mujeres") ": "¿fue aquélla más que referir sencillamente mi sentir con todas las venias que debo a nuestra Santa Madre Iglesia? Pues si ella, con su santísima autoridad, no me lo prohibe, ¿por qué me lo han de prolibir otros?" (Ob. cit., p. 468). Y éste no es más que el arranque para reanudar el tema, que es lo que evidentemente más le interesa: "¿Llevar una opinión contraria cle Vieira fue en mi atrevimiento, y no lo fue en su Paternidad llevarla contra los tres Santos Padres de la Iglesia? [Pablo, Cipriano, Agustín] Mi entendimiento tal cual ¿no es tan libre como el suyo, pues viene de un solar?" (ibid.) y "como yo fui libre para disentir de Vieira, to será cualquiera para disentir de mi dictamen" (Ob. cil., 1. $4(i)$ ).

IIay en Sor Juana Inés de la Cru\% un imperativo de claridad y de orden mental, no inferior al de la cultura, que sigue en pie siempre, en forma bien clara, anin cuando hacia el final de su vida parezca renunciar a todo en nombre de un ascetismo que, al no suprimirle su natural inquictud interior tan sugestiva, tampoco le priva sustancialmente de su exigencia intelectual; y es también una clara victoria sobre las pretensiones teologicas, que pueden aparecer exageradas, del gran jesuita portugués.

Que Nanuel Bandeira se interesase particularmente, en el campo de sus propias actividades literarias, por Sor Juana Inés de la Cruz, es un mérito que conviene senalar en orden a las relaciones actuales entre los mundos representados por las dos lenguas ibéricas en América. Y conviene tenerlo en cuenta por dos motivos: uno, de carácter cultural, y poético el segundo. Es de carácter cultural la extensa recapitulación y exposición que Manuel Bandeira lace de los distintos elementos que forman la personalidad humana y artística, además de la intelectual, de Sor Juana Ines de la Cruz, recapitulación y cxposición hechas con un evidente conocimiento del cstado de la crítica en torno a aquella gran figura: se sirve, de hecho, como de autorizadas piezas de apoyo, de nombres familiares a la erudición más rigurosa en torno a los mundos ibérico e iberoamericano en determinados aspectos específicos, desde Amado Nervo hasta Karl Vossler y Pedro Henríquez Ureña. Pero es el carácter poético

1 Ob. cit., p. 4.67 . 
el aspecto más importante del interés del poeta por aquella figura del siglo XVIr, sicuiera sea bajo la forma de una predilección implícita, pero completamente natural, hacia la índole humana $y^{\prime}$ la obra poética de aquella religiosa, sobre la que Bandeira trata de atraer la atención sirviéndose abundantemente, por un lado, de la interesantísina especie de autobiografía que es la liespucsla a Sor Filotea de la Cruz, y, por otro, de la actividad poética de la misma ${ }^{1}$.

Manuel Bandcira despla\%a quizá, si no precisamente en el orden, si en proporción a su importancia, los elementos que constituyen la personalidad de la gran autora mejicana del xir, dándonos en sintesis las iniciativas del final de su vida con las siguientes palabras:

at verdade que aos consclios de Dom Manuel se juntara a pressĩo do ambiente tormentoso do México nos primciros anos da décnda de yogo. Desgraças de têcla a sorte desabaram sôbre o país: assaltos de piratas no litoral, levautes de findios, epidenias, fone. Monnento chegron en que o mesmo conde de balve nito se sentia seguro no palício vice-reinal e procurou asilo no Convento de Sino lirancisco.

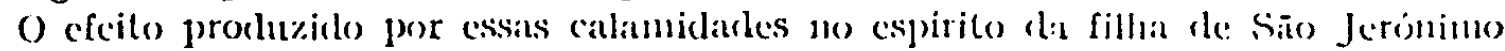
foi decisivo. $\Lambda$ reledada, a feminista, a mulher de poesiat e de ciencia cerleu lugar a santa que verdarleiramente havia nelat. Ao areebispo do Néxico entregon a suab biblioteca de quatro mil volumes, os seus instrumentos astronimicos e musicatia para que fússem venuliclos cm bencficio dos necessitatus, quedou-se pentente em sua cela nual, onde a 5 de março de $169+$ firmou com o pouprio sangue o protesto de renunciar aos estudos humuanos para trilhar o canninho da perfeiçĭo. Nāo deixou em sua cela señio tres livrinhos de devoçio e mutos cilicios e disciplinas. A cles se cutregou com tal paixio que o seu confessor, o bom Palre Nutònio, teve re intervir, desta vez para lhe moderar o ardor quase suicida. No ano seguinte as febres malignas que devastavan a populaçio do México irromperam na casa de Sāo Jerónimo. Juana Inés desvelou-se no tratanchto das irmäs até cair cla mesmia vitima do mal. Faleceu aos 17 de abril, com quarentaequatro anos de idide.

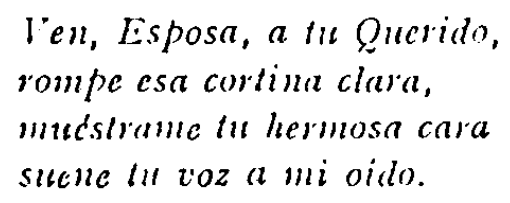

1 Iin este sentido danuleira hace suyo el juicio tradicional de sintesis que atribuye a los "autos sacranchtales" y a los "villancicos" de Sor Juana Incis de la Cruz la misma importancia que se reconoce a la obra de bernardo de balluena. "Obra [la poćtica de Sor Juana] que representa, conn a de Bernardo de Valbucna, a grande contribuigno hispano-ancricana ao barroco en literatura. O prema Grandeza Mcxicana, de Valbuena, é nĩo só barroco, mas americanamente barroco ('edro Ilenriquez. Ureña comparou-o à capela paroquial da Catedral de México)." Los escritos de Manmel Jandeira sobre la poetisa (pigginas informativas y criticas

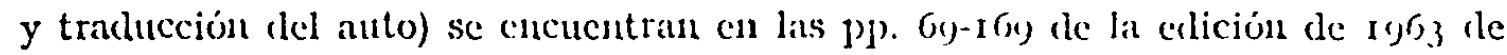
Estrela da larde (Rio, Livraria José Olympio İclitûra). Lil fragnento que ahora citanos pertencece a la p. $7^{6}$. 
Estava transposta a corrente de águas turvas: o divino Narciso revia-se finalmente, à luz da eternidade, na face desse grande poeta-mulher que terminou os seus dias terrenos morrendo como uma grande santa." (Ob. cil., pp. 88-89). Pero sobre todo, y esto es lo que mís nos interesa aqui, Bandeira sintetiza y fija, para consignarla a la historia de las relaciones culturales entre los mundos de ambas lenguas, española y portuguesa, del siglo xvir, la actitud de Sor Juana para con el l'. Vicira: -Contraditando a opiniño de Vicira, que sustentou: Cristo nño quis a retribuição do seu amor para si, mas para os homens, e esta a sua maior fineza: amar sem retribuiçāo, Juana Inés responde: Cristo quis a retribuiçño, e esta é a fineza. Manda Deus anar no próximo: quando, por anıor de alguém, se faz alguma coisa a favor de outrem, mais se preza aquele em cuja atençũo se procede do que aquele a quen se favorece. $O$ nio querer retribuiçio será fineza mun anor lıumano: porque seria desinterêsse; mis no de Cristo não o seria; porque êle não tem juterêsse algum em nossa retribuição. $O$ amor humano encontra na retribuiçūo algo que lhe faltava, mas a Cristo nada lhe falta, ainda que nūo lhe correspondanos. Assim, no solicitar a nossa retribuição sem ter necessidade dela é que está a fineza. Vieira, adverte Juana, nāo distinguiu entre retribuiçāo e utilidade de retribuiçūo. Cristo perguntou a Pedro: - Pedro, amas-me? -Sim. -Entāo apascenta as minhas ovellias. Bem porlia ter dito: - Pedro, amas as minhas ovellias? Pois apascenta-as. Mas nino diz isso e sim: Amas-me? Pois guarda as minhas ovelhas. I,ogo quis o anor para si c a utilidade para os homens." (Ob. cit., 1p). 86-87).

Pero obviamente la "Santa" interesa a Manuel Bandeira como poetisa no menos que como protagonista, tan eficaz cuanto infrecuentc, del mundo del pensamiento de su época expresado en lengua portuguesa en América (tanto más y mejor si este mundo del pensamiento se expresa al alto nivel propio de un $l$ '. Vieira). Bandeira se siente evidentemente atraido por la fuerza expresiva $y$ por la tensión sugerente del mundo poético de Sor Juana, claramente capaz de los más refinados recursos barrocos, pero con la sutileza de los "distingos» espirituales y formales que se remontan hasta Petrarca, en la espontaneidad cristalina de una superación del barroco mismo, gracias al rapto místico y, al mismo tiempo, a otras fuerzas de intensidad humana igualmente potentes.

Parece eviclente que Sor Juana ha suscitado una curiosidad especial, por parte de Manuel Bandeira, por cuanto se refiere a los «autos sacramentales", atracción ejercida de modo particular, entre los tres, por El divino $N$ arciso. Hay que suponer que la elección, por parte de Manuel Bandeira, poeta moderno, hay'a sido motivada más por el feliz éxito poético y artístico que por el género de inspiración, es decir, aquella consideración "a lo divino" - si así puede llamarse- o transformación religiosa, al estilo de Calderón, de una fábula antigua. 'Tanto es verdad que la atención le Nanuel Bandeira poeta, en la versión que él hace a su propia lengua de la "loa" introductoria y del auto mismo, aparece vinculada principalmente a las partes líricas, y más en concreto a la "loa» y a los "villancicos" contenidos en el auto: lo cual, por otro lado, pertenece a la lógica 
de las cosas. $\mathrm{Y}$ lo que merece ser puesto ell primer plino, como fruto de esta fatiga literaria refleja, de un poeta sobre otro poeta, son dos aspectos de la misma, los cuales, aún apareciendo distintos y a menudo incluso contradictorios, acaban coincidiendo sustancialnente, en el sentido de formar la smar ideal de los elenentos que componen las diversás modalidades con las que el traductor se ha acercado al original: es decir, la precupación de un artista de amoldarse en la forma a lo que está traduciendo a su propia lengua, con una fielcliclad absoluta al medio expresivo y, al mismo tiempo, con el cambio lógico de clima espiritual y artístico, de un modo humano de ser a otro y de una época a otra.

Realmente la traducción de Manuel Bandeira es completamente literal, dentro del espíritu de una escrupulosidad absoluta; pero, lo mismo que se dé cuenta de ello que en caso contrario (y quisiéramos decir que quizá no le importa, precisamente por el hecho de ser poeta, si merece o no darse cuenta de ello), la escrupulosidad de ma traducción literal responde y obedece, en el fondo y hasta en los menores matices formales. a un idcal sutil pero muy evidente: liberar el texto de todas sus sobrestructuras barrocas, y cllo, con el fin inplícito de trasvasarlo a una uneva atmósfera espiritual y artística. 'Trataremos de documentarlo ejemplificando nuestra impresión mediante la lectura de la traducción no ya de todo el auto en examen, sino de la "loa" que lo precede (y con esto nos eximimos de comparar también la traducción de los "villancicos" del auto, por ser éstos en mancra especial, como es sabido, ajenos al rebuscamiento y al jucgo de conceptismos y culteranismos de la ćpoca -y de la misma Sor Juana-, como fruto evidente que son de una emoción religiosa interior, particularmente cristalina en su forma ${ }^{1}$ ).

La intención, que nos parece poder atribuir a Manucl Landeira, arriba mencionada, aparece ya en la acotación que presenta la primera escena de la "loa». Lin el original español, ésta está caracterizada por matices de clegancia externa: todos ellos se pierden en la traducción portuguesa, en un afán de evidente simplificación que elimina elementos específicos, útiles incluso en la reconstrucción del folklore propio del tiempo y del lugar. Iil personaje "América», que en el original se presenta "Con mantas y cippiles, al modo (que se canta el Tocotín), pierde de hecho, en la rersión, los "cupiles", y al conservar las "mantas" no se hace referencia al detalle de que éstas adornan a aquel jersonaje "al modo que se canta el l'ocotin". $Y$ los "Indios e Indias", que bailan en el texto, lo hacen "con plumas y sonajas en las manos, como se hace de ordinario esta Danzan: todo cllo desaparece en la traducción, en la que sólo se habla de la presencia

1 Menćudez y l'elayo los aproxima, al menos como eco y reminiscencia, al Canlar de los Cantares y a otros ejemplos de la poesia bíblica. 
en escena de aquellos personajes, cuya danza viene precisada en el "Tocotín".

Enn la primera cantata del personaje "Música", en la invitación a los "Nobles Mejicanos" a que celebren "al gran Dios de las Semillas", se omite el detalle "cn pompa festiva" (v. I3 del original, p. 92 de la obra cilada del tracluctor ${ }^{12}$ ); la omisión es definitiva en la fórmula portuguesa con la que Manuel traduce el "Leitmotiv" del original: "y en pompa festiva, / celebrad al gran Dios de las Semillasl" ("Prestai reverência c louvor ( Ao grande Deus Seminador》). Y en este parlamento de la "Música" se suprime la precisión de "devotos" que acompana a los mejicanos (a cambio, hay una precisión temporal, uagora", que falta en el texto); finalmente, viene también onitida la imagen cálida de las "venas": "Dad de vuestras venas / la sangre más fina" ("Dai do vosso sangue / $A$ parle mais finai) (vv. 23-24; p. 92).

In el parlamento que sigue, del personaje "Occidente", la difusa imagen poútica, que en el texto original quiere dar una idea de los sacrificios humanos de aquel munclo, resulta descarnada y reducida a lo esencial: "... a quicu sacrifica / en sacrificios crucnlos / de sangre verlida" (vv. 3.t-3()) ("Eim sacrificios sangrcnlos", p. 93) (debe añadirse, sin enbargo, que presenta un aditamento, aún cuando éste pueda expresar otro concepto: "De crue $\approx a$ munca ouvida»).

Iin la traducción del parlamento siguiente, de "América" (vv. 43-70), es verdad que se conserva la imagen de la esterilidad del campo-en contraposición con la abundancia de las minas de oro-, pero ha desapareciclo el motivo que la determina: "sus [de las minas] fumosidades mismas" (v. 56).

Merece la pena detenerse en algunos de los pasos en los que se habla de la Eucaristía. El "Santo / Sacrificio de la Misa" (vv. 357-358), cuyo misterio la "Religión" trata de desvelar al "Occidente», se convierte en "cándidos accidentes" (p. I02), mientras la expresión de la "Santa Eucaristía" viene desplazada más adelante, siendo presentada como la causa de la transformación del trigo en la Carne y en la Sangre (de Cristo) (ulel trigo, cl cual se convicrle / en Su Carne y Sangre misman, vv. 36r362: "ulo trigo, o qual se converle / Pela Santa Eucaristia / Em sua Carne $e$ seu Sangu(", 102), desapareciendo, sin embargo, en la traducción, la precisación del texto original sobre la Sangre, "que en el Cáliz/está"

1 hel texto original damos el múmero progresivo de los versos; de la traducción damos la pilyina del rolumen citalo de las obras de Mannel Bandeira.

2 Jin la tradıcción de Manuel I3andeira hay un evidente error de imprenta: "Cuja Lslirpe antiga/Das limpidas luzes/Do Sol se originam" (p. 92). 
(vv. 363-364), concepto sustituido por otro carismático; "por divina fineza" (p. 102) ${ }^{1}$.

Lin el parlanento de "Occidente", en el que se dirige a lias gentes nuevas, todavia desconocidas, exclamando a su respecto: "upe asi dc mis alcgrias /quiercn impedir el curso?" (vv. III-II2), la elininación del adverbio "ast»" ("E de minhlas alegrias / Qucrem impedir o curso?》, p. 95) lleva consigo, obviamente, una atenuación. Jin forma antiloga, pierde algo de su eficacia la mayor correción gramatical intentada por Manuel Bandeira cuando éste, haciendo hablar a la "Religión" (que exige enérgicamente al "Celo" deje en vida al "Occidente" derrotado por aquél, porque ella, la "Religión", quiere convencerlo de la verdad que ella representa), se limita a traducir las palabras clel original "...mas el rendirla / con razón, me toca a mí" (vv. 215-2IG) del siguiente modo: "...mas reduzi-la / Pela razio me compcte / Com dosura persuasival) (p. 9S). Y una restricción de significado todavía, que bien pudiera parecer insignificante e incluso inexistente, pero que no es tal, a nuestro juicio: cn un determinado monento, "Anérica" siente el deseo de conocer las cosis de la "Religioun", las cosas cuyal existencia ésta le ha hecho escuchar: "....ya inspiración divina/me mucve a querer saberlas" (rv. 390-397); y Manuel I3andeira, al tralucir todo a la letra, hace, sin embargo, preceder un artículo que, disminuyendo la sensación de vaguedad, disminuye, a nucstro juicio, también tanto el ansia espiritual como el encanto poético: "...ja a inspiraşão divina... (p. 10.3). Lin el parlanento con el que "América", negándose orgullosamente a dejarse convencer por la "Religión" cristiana, trae a colación, en un típico clima de Siglo de Oro y ell especial de Calderón, el "albedrio»: "mi albedrio / con libertal más crecida / adorari mis Dcidades!» (vv. 23t-236), Manuel Bandeira no se preocupa de ello, linitándose a hacer decir al personaje: "ditorarci os meus Dcuscs" (p. 99). Otra atenuación en cl tono pucde destacarse cn el traslado de una afirmación de "América", que habla en plural, del original a la traducción: "... convencidas / estamos..." ( $\vee v .33 S-339)$, phural que Manuel Bandeira no respeta: "convencila cslou" (p. I02) ${ }^{2}$. Algún

1 Iin alguna ocasión, annque se mantienen las mismas palalmas, hay al mismo ticmpo un cambio en el significado: "OOh IIidra,/que viciles por sicle bocas, I de tu ponzoña nociva/loda la morfal cicula!" ( $\cdots$. 26G-269), lamento de la "Religionn., ante la obra del lispiritu del Mal, que Manuel Bancleira traduce asi: "O Hidra./ Que verles por sele bocas/Tua peçonha nociva/Mlais morlal do que a cicula!n (p. 10o).

2 Lo contrario succle a propúsito del "Occidente", en otro pasaje, cuanclo "Occidente" alirma que sabe que debe slavarsen antes de acercarse a la divina mesa de la lincaristia: "lengo de lavarme/que ast es mi costumbre antigua") (vv. 385386); y Manuel Bandeira se contenta con atribuir a la "Religión el propósilo de hacerlo: c...tenho de lavar-we, / Como é nossa usanca antiga» (p. Io3). 
concepto, finalmente, queda suprimido, como el expresado por la «Religión", quien, discutiendo con "América", afirma en cierto momento la necesidad de hacerle conocer la doctrina de San Pablo: «De Pablo con la doctrina/lengo de argiiirn (vv. 290-28r); y Manuel Bandeira se contenta con atribuir a la "Religión" el propósito de hacerlo: «valendo-me da doutrina / De P'aulo, argïircin (p. 100).

Pero nos detenemos aquí para no cansar ulteriormente al lector. Queremos destacar, sin embargo, con algún ejemplo la que juzgamos la segunda característica, la sumisión absoluta al texto, tan evidente que el extranjero familiarizadlo con ambas lenguas ibéricas puede avanzar en su lectura pasando con indiferencia sus ojos, del texto original a la traducción, sintiéndose atraido tan solo por las diferencias naturales entre las dos lenguas.

He aquí, por ejemplo, en el primer parlamento de la "Religión», una proposición objetiva española que da ocasión a la construcción personal del infinitivo en portugutés: "Cómo, siendo cl Celo tii, / sufren tus cristianas iras / ver que, vanamenle ciega, / celebre la Idolatria / con supersliciosos cullos / un idolo" (vv. 73-7S) se transforma en: "Como, sendo o Zelo tu, I Tuas católicas iras / Sofrim ver, vamente cega, / Celebrar a Idolatria / Com supersticiosos cultos / Um idolon(p. 94). También, en un pasaje donde habla "América": "Si cl pedir [por su parte] que yo no mulera" (v. 226), que se convierte cul: "Se o pedires que ch nao morra" (p. 99). Y finalmente - para acabar, pues podrían multiplicarse los ejemplos-: en otra intervención de "Almérica" dice ésta: "ulime: serí tan propicia / esa Deidal, que se deje / locar de mis manos mismas" (vv. 322-324); que el traductor traslada: "Dize, será tĩo propicia / Tal Divindade, que deixe / Tocaren-no estas maos minhas" (p. IOr).

Podemos incluir clentro de la característica de una escrupulosa adhesión al texto, por parte de Manuel Bandeira, su solicitud en hacer algunas precisiones cuando le parecen oportunas: también aquí nos limitamos a dar sólo algún ejemplo. Lin la primera aparición del "Celo" en eścena, el "Occiclente" queda suspenso ante su presencia y le pregunta: "Quién cris, que alemorizas / con sólo ver tu scmblante?" (vv. I39-I40); y Manuel Bandeira no escribe el pronombre de referencia directa: "Quen és, que me alcmorizas" (1). 96) 1 . Cuando el "Celo", en esta viva discusión entre él, "Atmérica" y $\mathrm{cl}$ "Occidente", habla de la tiranía de este último, precisando que "ioichlo que tus liranias / han llegado j'a a lo sumo" (vv. 147-

1 lin cambio, lie aquí nu cjemplo contrario: poco despućs anućrican, dirigivindose al "Celon, lo estimula así: ccesa en 1 intenlo" (v. 170); y Manuel Bandcira se limita a una con:trucción clemostrativa: "cessa esse intento (p. 97). 
148), Bandeira no se contenta con un simple "tiranias", sino que añade un "néscias": "...vendo / Tuas néscias tiranias / Chegar ao mais alto ponto" (p. 96). 'I’ambién aquí podemos dar cabida, como un aspecto más de precisión, al paso de un estínulo indirecto por parte de la "Religión" al "Celo": "Cese tu justicia, / Celo; no les [los españoles invasores] des la mucrlc" (VV. 221-222); y Bandeira: "Suspende a tua justiça" (p. 99).

Pero, a veces, la precisión acaba convirtiéndose en un verdadero cambio, aunque éste cntre clentro del espíritu de escrupulosidad propio del traductor. Cuando el "Occidente" afirma que es la fucrza la que lo obliga a rendirse ante "Ancérica": "Yo ya dije que me obliga / a rendirme a li la fucrza (vv. 237-238), Manuel Bandeira hace que el "Occidente" se dirija directancnte a "América": "Ji te disse que me obrigas / A me render pela forfan (p. 99). $Y$ en el mismo parlamento liay un cambio relativamente nuás interesante: de la decidida afirmación de "Occidente", que intenta seguir fiel a la propia religión, "...annque cautivo gima, / no me polrás impcdir / que aci, cn mi corazön, diga / que venero al gran Dios ac las Scmillas!) ( $\vee v .2+3-246)$, Manuel I3andeira climina el concepto de sufrimiento del prisioncro, sustituyénclolo con el genérico de la frase: "l'or mais que me digas" (p. 99): I' no es éste el único cambio. Ėn otro lugar - para dar un ejemplo diverso- la forma de interrogación retórica con la que "América" proclanna la existencia de un solo Dios bicnliechor: "¿Ves cómo no hay" otro Dios / como Aquéstc, que confirma/en beneficios Sus obras?" (vv. 277-2So) deja su puesto sin más a un tipo de afirmación pura y simple: "Ves que oulro Deus nĩo exislc, / Como ésle, que nos confirma/cm javores snas obras". (p. Iov). A veces puede hablarse, sin más, de malentendidos; nos limitamos a algunos ejemplos. Al conienzo del parlamento de "Occidente" que estamos comentando, Nanuel Bandeira quizá no haya entendido un concepto del texto ("lues culre todos los Dioses / que mi cullo solcmniza", vv. 29-30), que se convierte en "Pois que entre todos os Deuses / Que meu cullo solemnizam" (p. 93), haciendo ver que el sujeto "mit cullo" ha sido convertido en objeto. l'ambién aparece mal interpretado otro paso del mismo parlamento ("...entre todos mira / mi alención, como a mayor, / al gran Dios de las Semillas", vv. 40-43), que se convierte en: "...mais admira / Minha aten çio como ao maior / 0 grande Deus Seminador')-(p. 93), porque el significado del portugués "admirar» es evidentemente clistinto del español "mirar». $Y$ un error más en un paso en el que la "Religión" se refiere a los Misterios ("De "n Aulo en la alcgoria, / quiero mostrarlos [los misterios] visibles», VV. 4I84I9), que es traducido: "De um Aulo na alcgoria/Quero mostrar os visivcis" (p. I04), en el (que "os visiveis" se refieren al auto y 110 a los Misterios... 
Podrian hacerse nuevas observaciones, sobre elisiones o aditamentos, que en realidad sólo servirían, como contraste, para confirmar ulteriormente la atención sistemática y escrupulosa de Manuel Bandeira al texto. Cuando "América", deseosa ya de recibir la nueva religión, pide a esta última algunas precisiones diciendo: "pues ya inspiración divina / me mucve a quever saberlas" (vv. 396-397), el "Occidente" apremia: "Y yo; y mais..." (v. 398), Manuel Bandeira se limita al "e mais" (p. r03), suprimiendo la eficacia evidente del "y yo" del original. İn otras ocasiones, por el contrario, añade algunas cosas. Cuando la "Religión» subraya el contraste entre las riquezas del "Occidente" y de "América" por un lado y la vida miscrable que llevan por otro, dice: «... vivis tan miserables / enlre las riquezas mismas" (vv. I03-I04), Manuel Bandeira añade un "mirificas" a "riquczas" (p. 95). Y un ejemplo final: las naciones "osadas" de las que habla "América", dirigiéndose en un determinado momento al"Occidente", se convierten en Manuel Bandeira en "por denais ousadas"(p. 97) ${ }^{1}$.

Pero es justo of recer también algún ejemplo de libertad en la traducción.

$A$ este propósito pueden citarse los pequeños fragmentos formados por los versos 257-260 y 330-337, en los cuales Manuel Bandeira se ha alcjado realmente del texto. En el primer paso, el "Occidente" habla así del Dios cristiano: "iMira tii si puede haber, / en la Deidad más benigna, / mis bencficios que haga / ni mais que yo te repila!n; que Manuel 13andeira traduce: "Dizc-me se pode haver / Divindade mais benigna, / Quc mais buncficios fasa / Na sua glória infinita" (pp. 99-I00). Iìn el segundo fragmento, la "Religión" trata de hacer comprender a "América"

1 Podriamos continuar aún. I, a expresión "ya...yan, traducida en una ocasión literalmente con ujá...ján (vv. 37-38 del original; p. 93 de la traducción) ( "ya las entrañas que pulsan, / y'a el corazón que palpita "Jd as entranhas, que estremecem, / Ji o coraşâo, que palpitan), en otra ocasión queda reducida a la simple conjunción oen: a...j'a levantado el brazo, / ya blandida la cuchilla" (dice en una ocasión el "Celo" a la "Religión", vv. 83-84), y Manuel Bandeira: a...levantando o braco / E brandindo a minha espada" (p. 94) (precede un iján, que alguien pudiera pensar correspondiese, en la intención de Manuel Bandeira, al primer "yan del original; pero que no es así, porque el traductor lo ha unido al poisu inicial del período, scparándolo resueltamente del contexto por medio de una coma: "Pois $j a$, levantando..."). Y al término de la "loa", donde el "Celo" sugiere que se pida venia a los Reales Pies» (v. 473), Manuel Bandeira hace una curiosa distinción: invita a ponerse a les pies de la Reina, sí, pero para esto ha eliminaclo precedentemente al Rey...: "Celo" *...a los Reales Pies, / en quien Dos Mundes se cifrun / pidamos perdón postrados"; "Religión" uy a su Reina esclarecida", -América" "cuy'as soberanas plantas/besan humildes las Indias" (vv. 473-478); que Manuel 13aulcira traduce: "\%elo" "Sendo assim, ao Rei magnanimo / Em quem dois MIundos se cifram / P'climos perdio, prostrados.n / "Religiñon "É à Rainha esclarecida, .América" "Cujas soberanas planlas / Beijam humildes as Indias" (pp. ro5-106). 
la doble naturaleza, humana y divina, del Dios cristiano: "Aunque su Escncia Divina / es invisible e inmensa, / como Aquéste cstí ya unilla / a muestra Naturaleza, / tan Humana se avecina / a nosotros, que permite / que lo toquen las indignas / manos de los Sacerdolesn, y Manuel Bandeira: "Se bem sua Essência Divina / Scja invisivel e imcnsa, / Como aquela que está unida / à nalurcza dos homens, / Täo hutmana se avizinha/De nós, porém, que permite / Tocarem-no as mios indignas / Dos Saccrilotes do culton (pp). Ior-102). Un ejemplo más, aunque sea menos significativo: siempre hacia el final de la "loa", cuando el "Celo" confia a la "Religión" sus propias dudas de que el auto del Divino Narciso, habiéndose escrito en Méjico, se represente en Madrid, el original dice: "L'ucs dime, Religión, ya / que a eso le disle salidal (vv. 457-458), y Manuel Bandeira traduce: "Ora, dize, Religiño / Tu que, sábia, tulo cxplicas" (p. 105). Y para acabar: en el último parlamento del "Occidente", antes de que todos intervengan para cerrar el auto con el "Leitmotiv», el texto del romancillo "dicicndo que ya/conocen las Indias / al que es Verdadero/Dios de las Scmillas" (vv. 489-493), es traducido por Manucl Bamdeira con una cicrta libertad cu la forma siguiente: "Dizendo que já / Sabe a minha dila / Qual a verdadcira / Pessoa Divina" (p. I06). Hay aqui, en el parlamento de "América", anterior al que acabamos de citar, un detalle de Minnuel Bandeira que debemos colocar entre la humildad del hombre y la visión estética del artista: "América", cuando, en cl original, pide venia "l sus [entiendase: del Hemisferio del que antes ha hablado la "Religión"] ingenios", ha utilizado el término "ingenio» incluso para sí misma (vv. 48I-483), Nanuel Bandeira sustituye, en la traducción, cl término "insucrio" por el de "cstro»: "Aos Engenhos, / a quem humilde suplica/Mcu/estro"(p. Io6).

El afán de simplificación - en el sentilo de una liquidación de las sobreestructuras barrocas, para entendernos- $y$, al mismo tiempo, la escrupulosidad de la fidelidad al texto no han impedido a Manuel Bandeira una intervención, por otro lado notable y decidida. De hecho, ha suprimido la subdivisión en escenas, convirtiéndose la exposición, gracias a él, en algo continuo y sin las interrupciones motivadas por la técnica teatral. Hay razón para pensar que la causa que la originado tal aportación pueda obedecer al hecho de que el poeta haya sentido el auto en clave más bien lírica que dramática. Podría también pensarse que el poeta de hoy haya querido presentarnos el auto, a través de su intervención, en un clima diverso de aquel en el que fue escrito y con un objeto también distinto, es decir, en una atmósfera y con una finalidad modernas, que ya no corresponden, al menos en un aspecto total, a las prinitivas. 